\title{
Investigation of changes in the physical properties of the sandy soil in geotechnical control of the road embankment
}

\author{
Olga Yanina ${ }^{1, *}$, Anton Chigarev $^{1}$, Alexander Yanin ${ }^{1}$, Peter Kalugin ${ }^{1}$ and Yanina Yanina ${ }^{1}$ \\ ${ }^{1}$ Voronezh State Technical University, Moskovskiy prosp, 14, 394000, Voronezh, Voronezhskaya \\ obl., Russia
}

\begin{abstract}
The aim of this work is to determine the effect of "temperatureprecipitation" climate parameters on the physical properties of sandy soil of an embankment during the construction period. The object of this study is sand from a quarry and the upper layer of the road embankment before and after the climatic effect during the "autumn-winter-spring" period. The results of this study revealed changes in sand gradation, coefficient of permeability and void ratio of a sandy soil after the influence of "temperature-precipitation" climate parameters during a short time period. The results of this study can be used for geotechnical control of construction process.
\end{abstract}

\section{Introduction}

One of the tasks of engineering and geological research during the design and construction of modern roads is to study the properties of sandy soils which can be used for embankment. Physical properties of sand affect the stability and strength of the embankment and, consequently, road maintenance [1-5].

\section{Materials and methods}

Laboratory studies of physical properties have been carried out with four samples of sandy soil which was used for the construction of a road section in the Voronezh region of the Russian Federation. The first sample of sand was taken from a quarry of building materials. That sample was not exposed to climatic effect and had natural physical properties (sand gradation, water content, soil density). The second sample is quarry sand after performing a standard compaction. The third sample of sand was taken from a depth of $0.20 \mathrm{~m}$ from the surface of the road embankment after its compaction with construction equipment to the maximum dry soil density. The fourth sample of sand was taken from a depth of $0.20 \mathrm{~m}$ after seven months on the same section of the road after exposure to atmospheric precipitation and variable temperatures.

\footnotetext{
*Corresponding author: yaninaoi@yandex.ru
} 
For laboratory studies, 15 probes were taken from each sample of sand. According to the standard methods [6-8], under the Russian State Standard (GOST) the sand gradation, water content, soil density, coefficient of permeability and maximum dry soil density were determined for each sample of sand. The samples were classified, and their identifying names were found out [9]. The test results were obtained and processed by statistical methods [10].

\section{Results}

According to the sand gradation determination of the samples 1-4, Fig. 1 represents the plot of cumulative grading curves.

The plot analysis shows that the sand gradation from samples 1, 2 and 3 remained almost unchanged. Identifying name of sand (1-3) in composition is medium fine sand with a fraction content of $0.25-0.10 \mathrm{~mm}$ from $98.23 \%$ to $98.45 \%$. The sand gradation of sample 4 has changed after seven months of climatic exposure. Sample 4 is medium sand, the fraction content of $0.50-0.25 \mathrm{~mm}$ is $58.38 \%$. The sand texture of sample 4 has probably changed due to the elution of fractions of $0.25-0.10 \mathrm{~mm}$ and $<0.10 \mathrm{~mm}$ from the upper layer of the embankment during seasonal precipitation and snow melt.

Fig. 2 shows the plot of the coefficient of permeability change for sand samples $1-4$ during the construction of the road section.

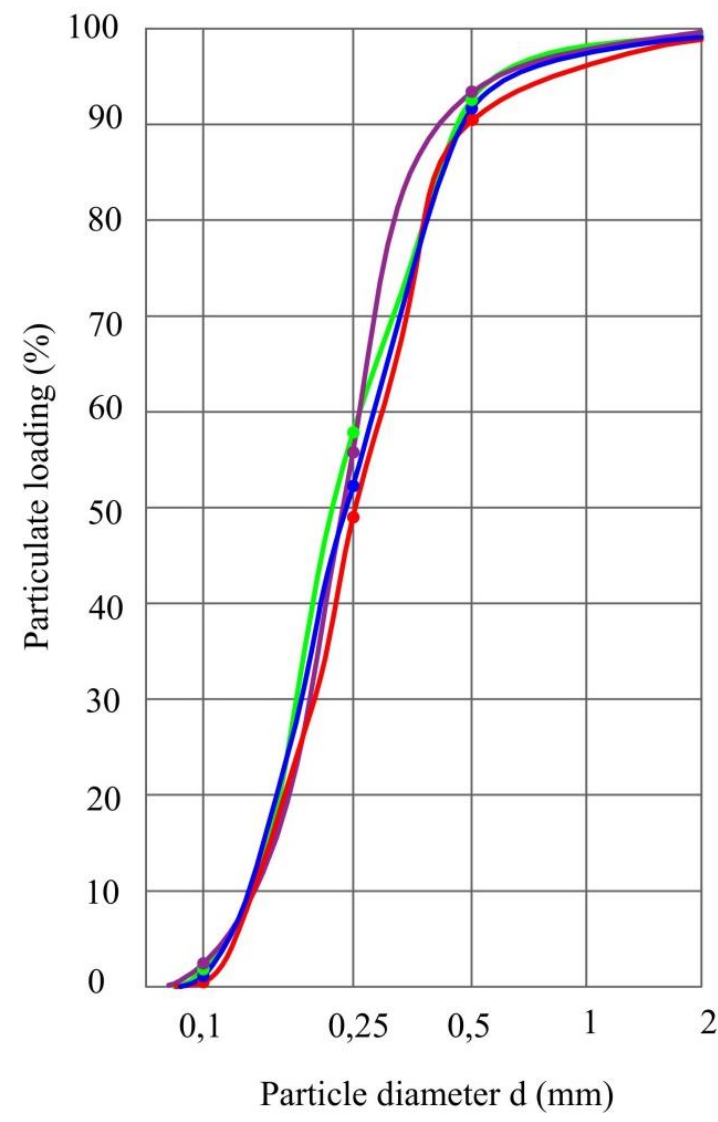

Symbols

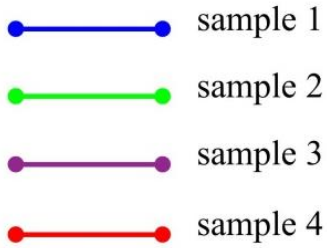

Fig. 1. Cumulative grading curves for samples 1-4. 


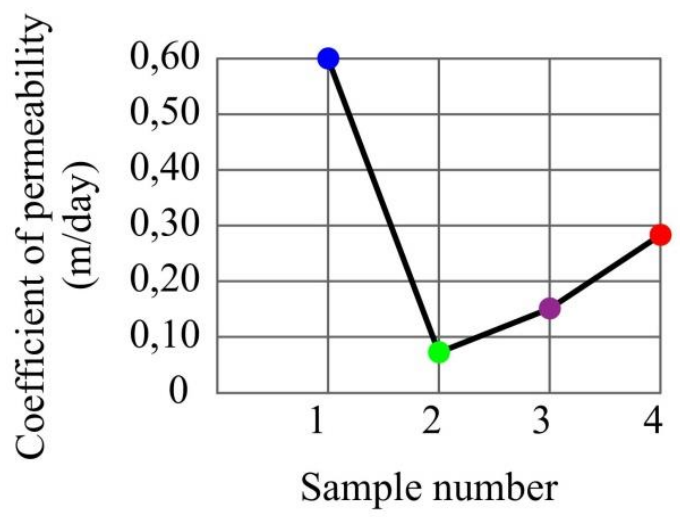

Fig. 2. Coefficient of permeability change for samples $1-4$.

The plot analysis shows that after a standard compaction in the laboratory the sand coefficient of permeability of sample 2 is decreased almost by 9 times in comparison with sample 1 . Therefore, sample 2 after its compaction to the maximum dry soil density can't be placed in the group of drainage sand, because the standard requirement for a coefficient of permeability, which is not less than $0.5 \mathrm{~m} /$ day, is not satisfied. The sand coefficient of permeability of sample 3 for a given value of the coefficient of consolidation 0.95 is increased by $114.3 .0 \%$ in comparison with sample 2 . The value of the sand coefficient of permeability of sample 4 after exposure to seasonal "temperature - precipitation" climate parameters is increased by 2 times in comparison with sample 3 at the beginning of construction works. The increase in sand coefficient of permeability of sample 4 is related to a sand gradation when the dust particles are washed out and the decompaction process of the upper part of the embankment during the "autumn-winter-spring" period.

The values of the void ratio for samples 1 - 4 [4] were calculated based on the results of soil density and water content determination. Changes in the values of the void ratio during the construction process of the road embankment are shown in Fig. 3.

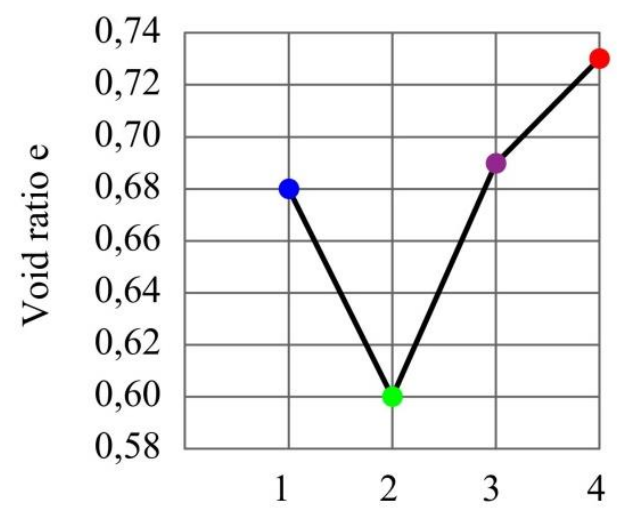

Sample number

Fig. 3. Void ratio change for samples $1-4$.

Samples 1 - 3 are medium fine sands of medium density. The values of sand void ratio vary from 0.60 (standard compaction) and up to 0.69 (embankment compaction at the beginning of work). Sample 4 is loose medium sand. After climatic exposure, the value of 
the void ratio of sample 4 was increased by $7.4 \%$ as compared to its values at the beginning of embankment filling and compaction. That also confirms the presence of decompression process in the upper part of the embankment during the " autumn-winter-spring" period.

\section{Conclusions}

The present study revealed the change of the physical properties of the sand road embankment after seasonal "temperature - precipitation" climate parameters during the construction process.

The results of this study can be used for geotechnical soil control during the construction process [11].

\section{References}

1. E.S. Ashpiz, Path and track facilities 12, 16-18 (2014)

2. L.A. Smolyanitsky, A.V. Sycheva, Path and track economy 4, 20-21 (2012)

3. S.V. Alexikov, I.S. Alexikov, L.E. Kurdyukova, Bulletin of VolgGASU, Constrantion and architecture 12(31), 35-48 (2008)

4. L.A. Smolyanitsky, Vestnik VSU, geology 2, 225-239 (2006)

5. L.A. Smolyanitsky, A.E. Kurilovich Voronezh State University. Voronezh 2923-B92, 9 (1992)

6. The Russian State Standard GOST 12536-2014 (Standartinform, Moscow, 2015)

7. The Russian State Standard GOST 25584-2016 (Standartinform, Moscow, 2016)

8. The Russian State Standard GOST 22733-2016 (Standartinform, Moscow, 2016)

9. The Russian State Standard GOST 25100-2011 (Standartinform, Moscow, 2013)

10. The Russian State Standard GOST 20522-2012 (Standartinform, Moscow, 2013)

11. Y.A. Yanina, O.I. Yanina, Condition and prospects of the development of modern science: socio-economic, natural-science research. Digest of articles (Publishing House "Privolzhsky House of Knowledge", Penza, 2016) 